\title{
ULTIMATE STRENGTH FORMULATIONS OF STIFFENED STEEL PANELS UNDER IN-PLANE COMPRESSION OR TENSION WITH CRACKING DAMAGE
}

\section{R. Zareei ${ }^{1}$, M. Iranmanesh ${ }^{2 *}$}

${ }^{1}$ Department of Maritime engineering, Amirkabir University of Technology, Tehran, Iran, Email: mrzarei@ aut.ac.ir ${ }^{2}$ Department of Maritime engineering, Amirkabir University of Technology, Tehran, Iran, Email: imehdi@ aut.ac.ir, *Corresponding Author.

\begin{abstract}
:
The aim of the present study is to develop closed-form formulations for predicting the ultimate compressive and tensional strength of stiffened steel panels with crack damages. At first, a numerical database is generated. This database includes the ultimate strength levels of stiffened steel panels with cracks subjected to axial compressive or tensile loads. It was carried out with a series of nonlinear FEM analyses by varying the size of crack damage. Then, based on this numerical database, regression analysis is used for deriving the empirical formulations. The results of the present paper can be used for the reliability and risk assessment of stiffened steel panels with cracks.
\end{abstract}

Keywords: Ultimate strength, empirical formulation, axial compression and tension, cracked stiffened panel, initial imperfection, nonlinear FEM, regression analysis.

\section{NOMENCLATURE}

\begin{tabular}{|c|c|c|c|}
\hline$A_{0}$ & Intact cross section area of stiffened panel & $b(=B)$ & Plate breadth \\
\hline$A_{C}$ & $\begin{array}{l}\text { Remaining cross section area of cracked } \\
\text { stiffened panel }\end{array}$ & $r$ & $\begin{array}{l}\text { Radius gyration of a stiffener with its } \\
\text { attached plating }\end{array}$ \\
\hline E & Young's modulus & $C_{1}-C_{5}$ & Constant coefficients \\
\hline$U_{i}$ & Displacement along $\mathrm{i}$-axis $(\mathrm{i}=\mathrm{X}, \mathrm{Y}, \mathrm{Z})$ & $I$ & $\begin{array}{l}\text { Moment of inertia of a stiffener with } \\
\text { its attached plating }\end{array}$ \\
\hline$R_{i}$ & Rotation about i-axis $(\mathrm{i}=\mathrm{X}, \mathrm{Y}, \mathrm{Z})$ & $z_{0}$ & $\begin{array}{l}\text { Distance between outer surface of plate } \\
\text { and neutral axis of plate-stiffener }\end{array}$ \\
\hline$a_{p}$ & Half crack length in plate & & \\
\hline$a_{w}$ & Crack length in stiffener web & \multicolumn{2}{|c|}{ Greek symbols } \\
\hline$h_{w}$ & Web height of longitudinal stiffener & $v$ & Pois on ration \\
\hline$t_{w}$ & Web thickness of longitudinal stiffener & $\sigma_{X}$ & $\begin{array}{l}\text { Compression or tension stress in } \\
\text { longitudinal direction }\end{array}$ \\
\hline$b_{f}$ & Flange breadth of longitudinal stiffener & $\sigma_{Y P}$ & Plate yield stress \\
\hline$t_{f}$ & Flange thickness of longitudinal stiffener & $\sigma_{Y S}$ & Stiffener yield stress \\
\hline$t_{p}(=t)$ & Plate thickness & $\sigma_{Y}\left(=\sigma_{Y s e q}\right)$ & Yield stress \\
\hline$w_{s}$ & Column-type initial deflection of stiffeners & $f_{0}$ & $\begin{array}{l}\text { Side-ways initial deflection of } \\
\text { stiffeners }\end{array}$ \\
\hline$m$ & $\begin{array}{l}\text { buckling mode half wave number in the } \mathrm{X} \\
\text { (longitudinal) direction }\end{array}$ & $s_{U l t}$ & Ultimate strength \\
\hline$w_{p}$ & Initial deflection of plate & $s_{U l t} / s_{Y s e q}$ & Non-dimensionalised Ultimate strength \\
\hline$w_{0 p}$ & Maximum plate initial deflection & $l$ & Column slenderness ratio \\
\hline$L$ & Plate length & $b$ & Plate slenderness ratio \\
\hline
\end{tabular}




\section{Introduction}

In recent years, there has been a trend towards limit-state design instead of the traditional allowable stress design. Ultimate strength is one of the most important limit states considered for steel-plated structures (Paik and Thayamballi, 2003). Stiffened panels are the main part of marine and civil steel structures such as ships and bridges. The ultimate bending moment of the ship hull girder is associated with the compressive and tensile ultimate strength of stiffened panels between bulkheads or web frames and unstiffened plates between stiffeners (Hu et al., 2004). Defects of cracks are inherent in structural components - they are either present during production or developed under service load (Wang et al., 2015).

Cracks can affect the load-carrying capacity of stiffened panels and therefore the entire structure. As steel structures get older, the effect of cracks on ultimate strength analysis should be considered properly. Within the scheme of the ultimate limit state-based risk or reliability assessment for aging structures, closed-form expressions are required for predicting the ultimate strength of structural members, taking into account the primary damage effects (Paik and Kumar, 2006).

A number of studies have been previously carried out on the strength behaviour of cracked unstiffened and stiffened plates in the literature. Paik et al. (2005) carried out experimental and numerical research on the ultimate strength of cracked steel plate elements subjected to axial compressive or tensile loads. They suggested a simple formula for predicting the ultimate strength of the cracked plate elements under axial compression or tension, based on the reduced cross-sectional area due to the cracking damage. Paik and Kumar (2006) numerically studied the ultimate strength-reduction characteristics of a stiffened panel with cracking damage under axial tension or compression. In this study, as in the previous ones, a possibly simpler and more intuitive model to predict the ultimate strength of a cracked panel subjected to tensile loads was suggested. Paik (2008 and 2009) studied the residual ultimate strength of steel plates with longitudinal cracks under axial compression with varying crack size and locations by experimental and numerical approaches respectively. In this article, it is found that the previously suggested formula can estimate the ultimate strength of steel plates with longitudinal cracks under axial compression on a very conservative side. Wang et al. (2009) numerically investigated the residual ultimate strength of structural members with multiple crack damage.

This paper presents simplified models for predicting the ultimate strength of multi-cracked structural members. Margaritis and Toulios (2012), through a series of nonlinear finite element analyses, studied the ultimate strength and collapse response of stiffened plates with straight cracks. They compared the effect of the two element types, namely shell element and brick element, on the ultimate strength behaviour of stiffened plates. Bayatfar et al. (2014) numerically dealt with the influence of through-thickness cracks with no propagation in terms of length and location on the ultimate compressive strength characteristics of unstiffened and stiffened plate elements used in thin-walled structures. Rahbar-Ranji and Zarookian (2014) analysed the ultimate strength of stiffened plates with a transverse crack under uniaxial compression. The influence of various geometrical properties of stiffened plates was investigated, accounting for different crack sizes and locations. Xu et al. (2014) analysed the residual ultimate strength of stiffened panels with locked cracks under axial compressive loading. In this research, the influences of various geometrical characteristics of cracks and panels - such as the length and the orientation angle of cracks - are investigated through the nonlinear finite element analysis. Wang et al. (2015) numerically analysed the ultimate shear strength of intact and cracked stiffened panels. First, an empirical formula for the ultimate shear strength of intact stiffened panels is proposed. Vertical, horizontal, and angular cracks are considered and a simplified method for calculating the equivalent crack length is presented.

Finally, a formula for the ultimate shear strength of cracked stiffened panels is derived on the basis of the formula for intact stiffened panels. Cui et al. (2016) numerically investigated the ultimate strength reduction characteristics of steel plates due to crack damage under longitudinal compression with varying length, location, and orientation angle of cracks. They considered three types of cracks - trans verse crack, longitudinal crack, and inclined crack - and found that the minimum and the maximum ultimate strength values are obtained for the transverse crack and longitudinal crack respectively.

Despite extensive works on the ultimate strength analysis of stiffened panels, there are a few contributions to the formulation of the ultimate strength of cracked panels under compression or tension. The focus of the present paper is on the formulation of ultimate strength of intact and cracked stiffened panels under compression or tension loads. 


\section{Numerical database used for the derivation of empirical formulation}

\subsection{Structural arrangements and geometrical characteristics of stiffened steel plates}

Two databases of ultimate strength values are generated for the derivation of the ultimate compressive and tensile strengths of stiffened steel panels with crack damages. These databases may be developed based on experimental tests or numerical analyses. Here, a series of elastic-plastic large deflection analyses is performed by applying the finite element method (FEM) on stiffened panels by varying the size of cracking damage. A total of 1,344 and 1,120 prototype cracked stiffened steel plates are numerically analysed for calculating the ultimate compressive and tensile strength. All analysed stiffened panels have T-bar stiffeners, as shown in Fig. 1.

Two types of cracks have been considered, both located in the normal direction to the axial loading tension or compression. The first one is vertically oriented in the mid-length edge of the stiffener web at the junction of the web and the plate. The second one is trans versely oriented at the centre of the plate. Both of the cracks are assumed to be through-thickness cracks with a 3-mm gap between the crack faces. Crack propagation is not considered. The schematic view of a stiffened panel structure with crack damage under axial compression and tension loads is given in Fig. 2. $\mathrm{L} \times \mathrm{B} \times \mathrm{t}$ are the plate dimensions, $\mathrm{h}_{\mathrm{w}} \times \mathrm{t}_{\mathrm{w}}$ are the stiffener web dimensions, $b_{\mathrm{f}} \times \mathrm{t}_{\mathrm{f}}$ are flange dimensions, and $2 . \mathrm{a}_{\mathrm{p}}$ and $\mathrm{a}_{\mathrm{w}}$ are crack lengths in the plate and stiffener web.

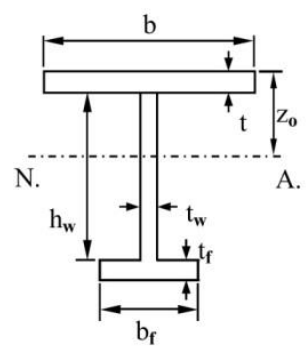

Fig. 1: Cross-sectional geometries of Fig. 2: Schematic view of a stiffened panel with crack damage stiffened panels

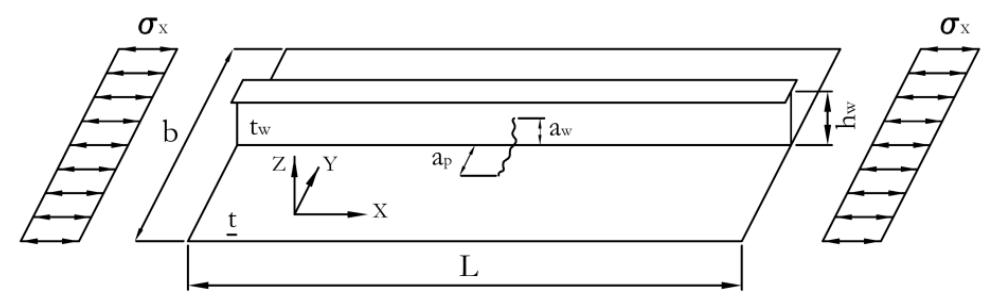

\subsection{Extent of the model, boundary conditions, and loading sequence}

The extent of the selected model is one of the most important issues related to the finite element analysis of stiffened panel. A one-bay plate-stiffener combination (PSC) model, as shown in Fig. 3, has been chosen for analysing the ultimate strength of stiffened panels.

Boundary conditions of the analysed stiffened panels, depicted in Fig. 4, are as follows:

- Symmetrical conditions on the longitudinal edges

- Simply-supported straight on the transverse edges

- Uniform compressive or tension displacement on the loading edge (the left-hand edge in Fig. 4)

- $\quad$ Restrained against in-plane movement on the opposite of the loading edge

After producing initial deflections in the stiffened plate, longitudinal compression or tension is applied on the stiffened plate.

\subsection{Finite element code and adopted elements}

The ultimate strength of the stiffened panels is assessed using ANSYS (2001). Both material and geometric nonlinearities are taken into account. From the library of the available elements of the ANSYS FEM program, the four-node SHELL181 element is used for the meshing of the stiffened plate models. SHELL181 is suitable for analysing thin to moderately thick shell structures, which fall into the domain of thickness of plates used for ship building (Bayatfar et al., 2014). The SHELL181 element has six degrees of freedom at each node-translations in the nodal $\mathrm{x}, \mathrm{y}$, and $\mathrm{z}$ directions and rotations about the nodal $\mathrm{x}, \mathrm{y}$, and $\mathrm{z}$ axes. This element was recommended for nonlinear structures by ANSYS (2001). Fig. 5 shows typical examples of the cracked stiffened panel mesh models. 


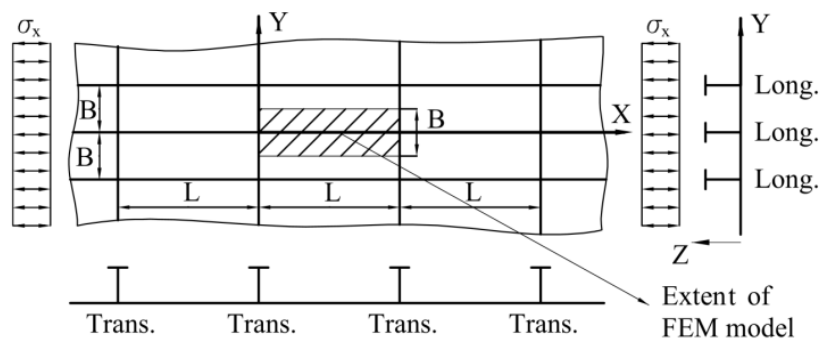

Fig. 3: Extent of the stiffened panel models for analysis

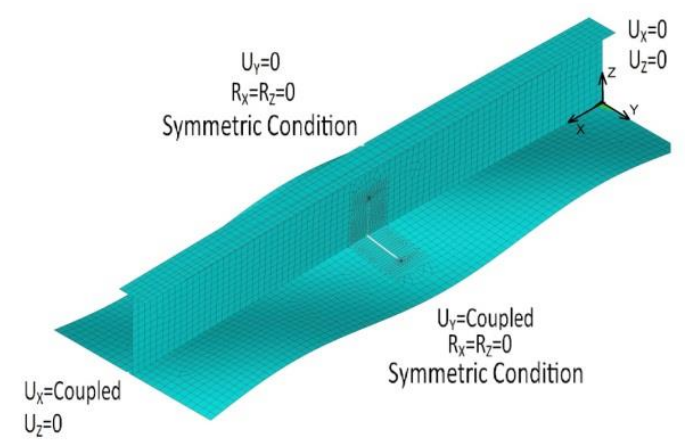

Fig. 4: Boundary condition of the stiffened panel models for analysis
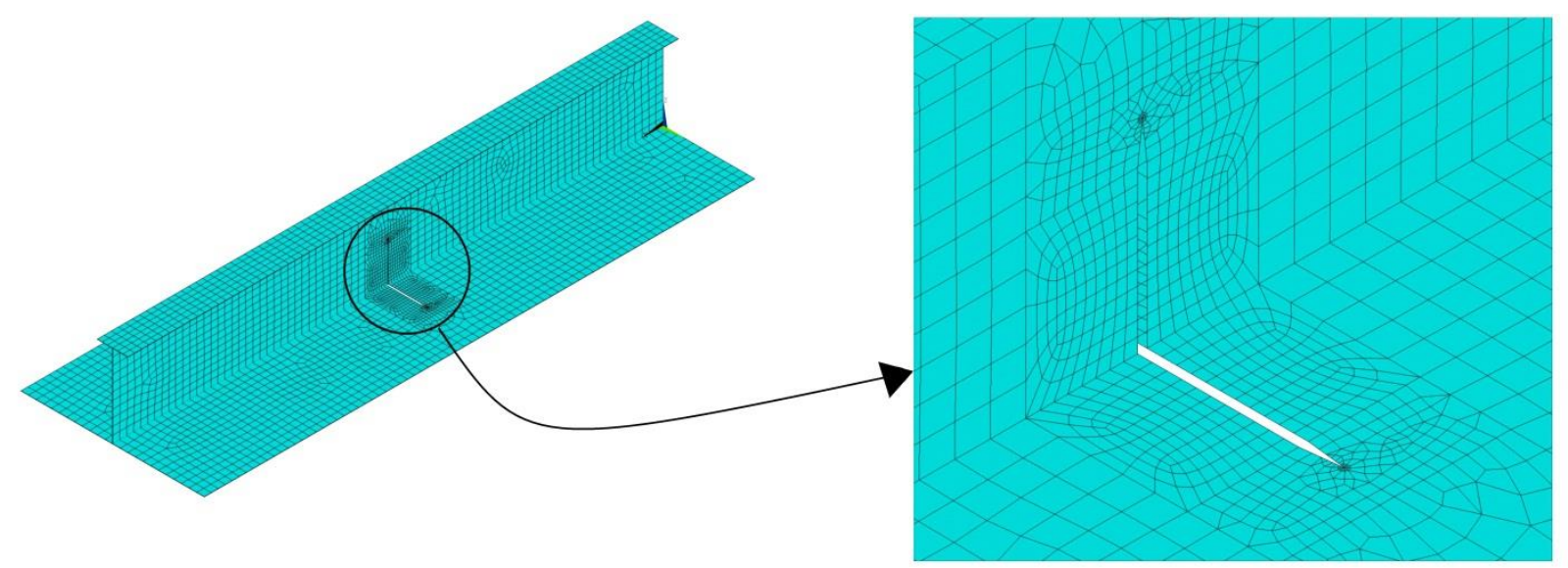

Fig. 5: Typical examples of the cracked stiffened panel mesh models.

\subsection{Mechanical properties of material}

The material of the plates used in steel-plated structures such as ships and offshore structures is normally either mild steel or high tensile steel, with yield strength being typically in the range of 230-450 MPa (Paik et al., 2005). The material used in this study is categorized as high-strength low-alloy (HSLA) steel with 350 MPa yield stress. Young's modulus and Poisson's ratio of the material are $205 \mathrm{GPa}$ and 0.3 respectively. For the ultimate compressive strength analysis of panels, an elastic-plastic material property is used. The stress -strain relationship of this material is shown in Fig. 6. On the other hand, elastic-perfectly-plastic material with zero strain-hardening is used for the analys is of the ultimate tensile strength. The influence of welding residual stress is not considered in the present paper.

\subsection{Initial distortions}

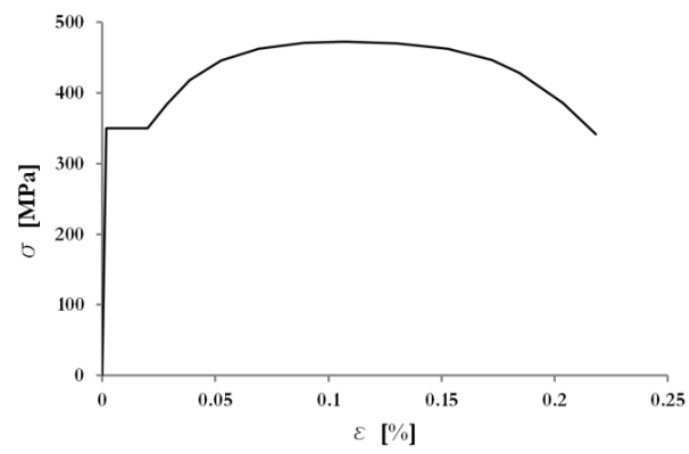

Fig. 6: Stress-strain behaviour of the material

Fabrications of stiffened panels usually develop initial imperfections such as initial deflections and residual stresses in steel-plated structures. The ultimate strength of stiffened panels is affected by fabrication-based initial 
imperfections; thus, the modelling shape and magnitude of initial imperfections are important. The influence of welding residual stress is not considered in the present paper. Generally, it is assumed that the initial deflection of panels has the same shape as the lowest buckling mode. In the present study, initial deflections of panels are generated on the basis of the combination of the following types. Three types of initial deflections have been considered.

- $\quad$ Plating initial deflection (Paik et al., 2004):

$w_{p}=w_{0 p} \sin \left(\frac{m p x}{L}\right) \sin \left(\frac{p y}{B}\right)$

$w_{0 p}=\begin{array}{cc}0.025 b^{2} t & \text { for slight level } \\ 0.1 b^{2} t & \text { for average level } \\ \text { 童 } 0.3 b^{2} t & \text { for severe level }\end{array}$

$\mathrm{L}$ and $\mathrm{B}$ are respectively the length and width of the stiffened panel, while $\mathrm{m}$ is the buckling mode half-wave number in the $\mathrm{X}$ (longitudinal) direction, which is equal to L/B. An average value of $w_{0 p}$ is used in the present paper. When LB is not an integer, $m$ is taken as the minimum integer satisfying the following condition (Kmiecik et al., 1995):

$L / B £ \sqrt{m(m+1)}$

- $\quad$ Column-type initial deflection of stiffeners (Fujikubo et al., 2005):

$w_{s}=\frac{L}{1000} \sin \left(\frac{p x}{L}\right)$

- Sideways initial deflection of stiffeners due to angular rotation about the panel-stiffener intersection line (Fujikubo et al., 2005):

$f_{0}=\frac{L}{1000 h_{w}} \sin \left(\frac{p x}{L}\right)$

Fig. 7 shows a typical shape of the initial deflection of stiffened panels with magnification of 10 times.
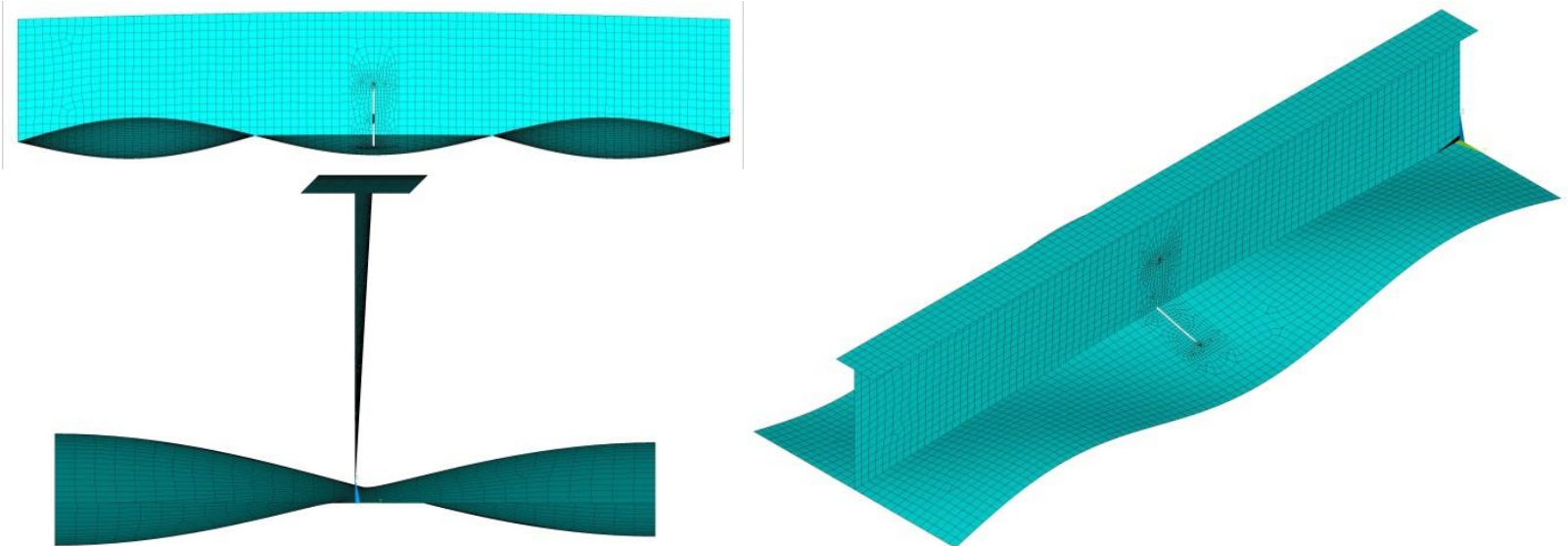

Fig. 7: Initial deflection of stiffened panel with 10 times magnification

\section{Verification of code and approach}

The validity of the present FEM is checked by comparis on between the present numerical computations of the ultimate strength and the experimental results described by Paik et al. (2005). Paik carried out an experimental study on the ultimate strength of cracked steel plate elements subjected to axial compressive or tensile loads.

For calculating ultimate tensile strength, Paik carried out a series of mechanical tests with artificial cracks of varying size and location and also varying plate thickness. Details of these tests can be found in the study by Paik 
and Thayamballi (2002). In the present study, only finite element analyses of the test structures with $1.6 \mathrm{~mm}$ of thickness and centre crack are performed. Schematics of the plate element tested with cen tre crack and its FEM are shown in Fig. 8. A comparis on between the ultimate strength values obtained by the FEM and by the experimental tests is shown in Table 1. As observed, a good agreement is seen between finite element analysis and test results in ultimate tensile strength calculation. Based on Table 1, finite element analys is can be used for the calculation of the ultimate tensile strength of steel plate structures with crack damage.

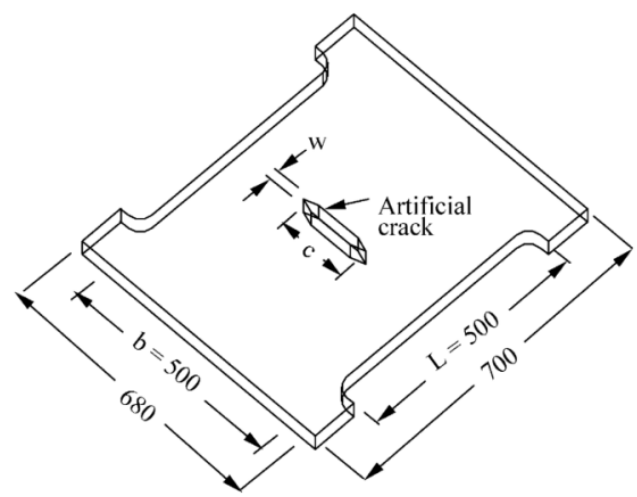

(a)

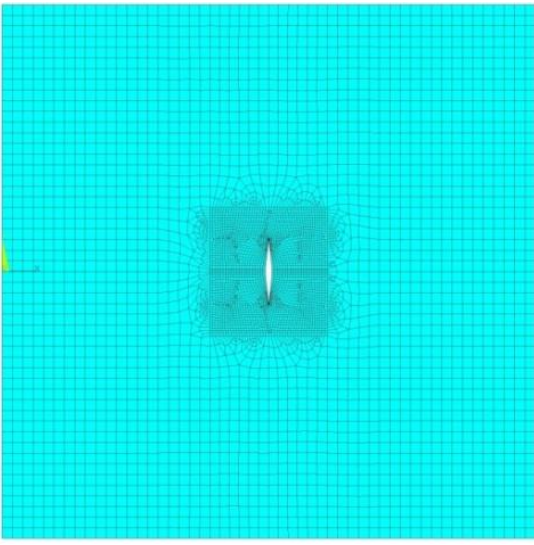

(b)

Fig. 8: A schematic of a plate element of Paik tests with center crack and finite element model

Table 1: Comparis on of FEM with test results of Paik in ultimate tensile strength

\begin{tabular}{|c|c|c|c|c|c|c|c|c|c|}
\hline $\begin{array}{c}\text { Specimen } \\
\text { number }\end{array}$ & $\begin{array}{c}\text { Yield stress } \\
(\mathrm{MPa})\end{array}$ & $\begin{array}{c}\text { Ultimate } \\
\text { tensile stress } \\
(\mathrm{MPa})\end{array}$ & $\begin{array}{c}\text { Young's } \\
\text { modulus } \\
(\mathrm{GPa})\end{array}$ & $\mathrm{t}(\mathrm{mm})$ & $\mathrm{c}(\mathrm{mm})$ & \multirow{2}{*}{$\begin{array}{c}\text { Ultimate tensile } \\
(\mathrm{mm})\end{array}$} & \multicolumn{2}{|c|}{\begin{tabular}{c} 
strength (MPa) \\
\cline { 6 - 11 }
\end{tabular}} \\
\hline NP16-15 & 296.1 & 362.1 & 198.3 & 1.6 & 15 & 3.15 & 295.75 & 296.87 & -0.38 \\
\hline NP16-30 & 296.1 & 362.1 & 198.3 & 1.6 & 30 & 3.15 & 286.64 & 292.67 & -2.10 \\
\hline NP16-60 & 296.1 & 362.1 & 198.3 & 1.6 & 60 & 3.15 & 271.88 & 275.06 & -1.17 \\
\hline
\end{tabular}

Ultimate compressive strength is also determined experimentally by Paik et al. (2005), apart from the ultimate tensile strength. A total of 10 box-type steel-plated structures with premised cracking damage and under axial compression in a quasi-static loading condition were tested by Paik. The size and location of the cracks were varied in each set. The test set-up and the schematic view of test structures are shown in Fig. 9. Three types of crack locations were considered, as shown in Fig. 10. These three types include centre crack (VC -Center), one-side crack (VC-Edge (1)) and two-side crack (VC-Edge (2)). Among the test specimens of Paik, two specimens VC0.330 and VC3.0-50 were chosen for the purpose of validation. FEM of the VC3.0-50 set is shown in Fig. 11. Average axial compressive stress-strain curves of thesetwo specimens are shown in Fig. 12. Fig. 13 represents the collapse modes of the specimens VC3.0-50, as obtained from tests and numerical simulations. The same collapse mode with more or less similar features is obtained experimentally or numerically for VC3.0-50 specimens. A comparison of the ultimate compressive strength values obtained by the FEM and by the experimental tests is given in Table 2. A strong agreement can be seen between finite element analysis and test results in the ultimate compressive strength calculation. From Table 2, it is concluded that finite element analysis is useful and can be used for the calculation of ultimate compressive strength of steel-plated structures with crack damage.

Table 2: Comparison of FEM with test results of Paik in ultimate compressive strength

\begin{tabular}{|c|c|c|c|c|c|c|c|c|}
\hline $\begin{array}{c}\text { Specimen } \\
\text { number }\end{array}$ & $\begin{array}{c}\text { Yield stress } \\
(\mathrm{MPa})\end{array}$ & $\begin{array}{c}\text { Young's modulus } \\
(\mathrm{GPa})\end{array}$ & $\begin{array}{c}\text { Gap of crack, G } \\
(\mathrm{mm})\end{array}$ & $\begin{array}{c}2 \mathrm{c} \\
(\mathrm{mm})\end{array}$ & $2 \mathrm{c} / \mathrm{b}$ & \multicolumn{2}{|c|}{$\begin{array}{c}\text { Ultimate compressive } \\
\text { strength }\end{array}$} & \multirow{2}{*}{$\begin{array}{c}\text { Diff. } \\
(\%)\end{array}$} \\
\hline VC 0.3-30 & 245.45 & 197.5 & 0.3 & 150 & 0.30 & 102.89 & 105.66 & -2.69 \\
\hline VC 3.0-50 & 245.45 & 197.5 & 3.0 & 250 & 0.50 & 92.65 & 98.62 & -6.44 \\
\hline
\end{tabular}



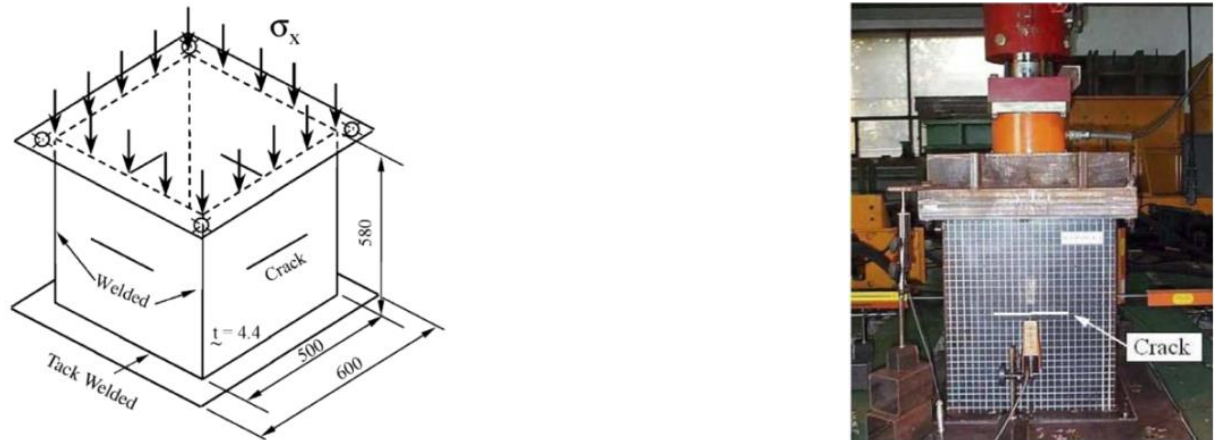

Fig. 9: Test set-up and schematic view of Paik test structures in compressive load
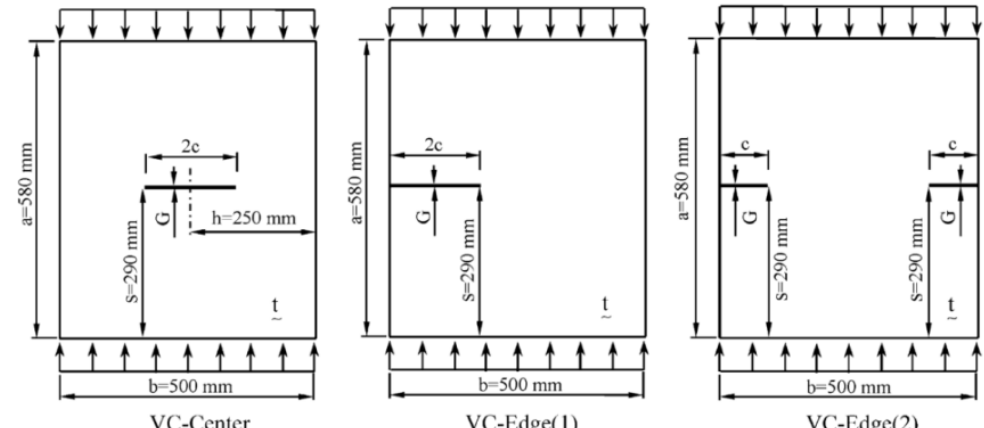

Fig. 10: Various crack location in test structures

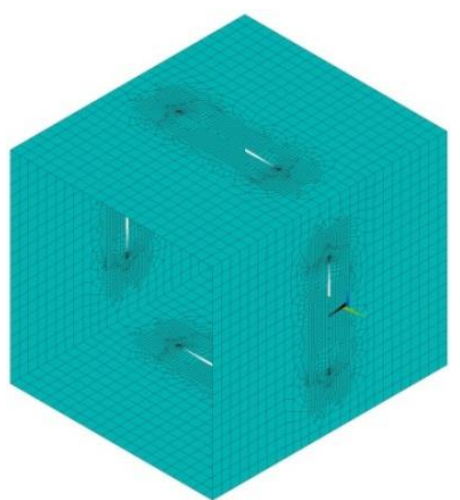

(a)

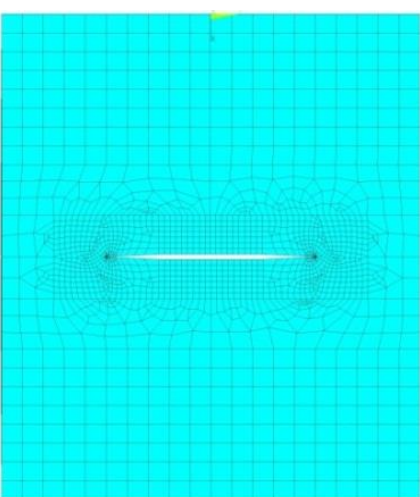

(b)

Fig. 11: Finite element model of VC 3.0-50 set, a-Isometric, b-One plate view

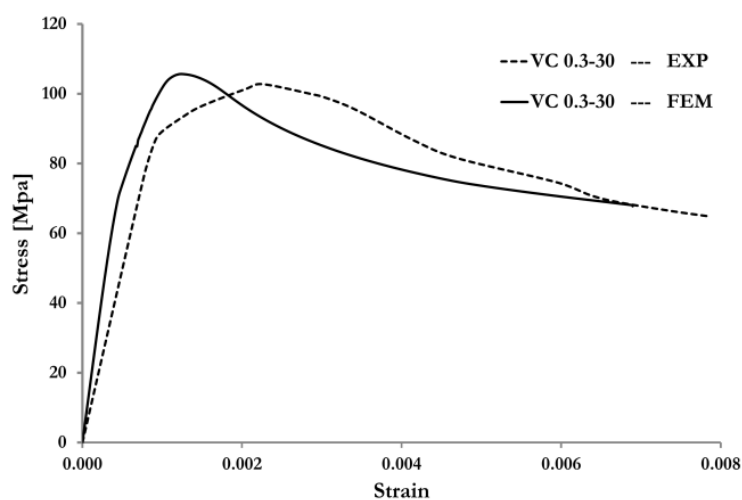

(a)

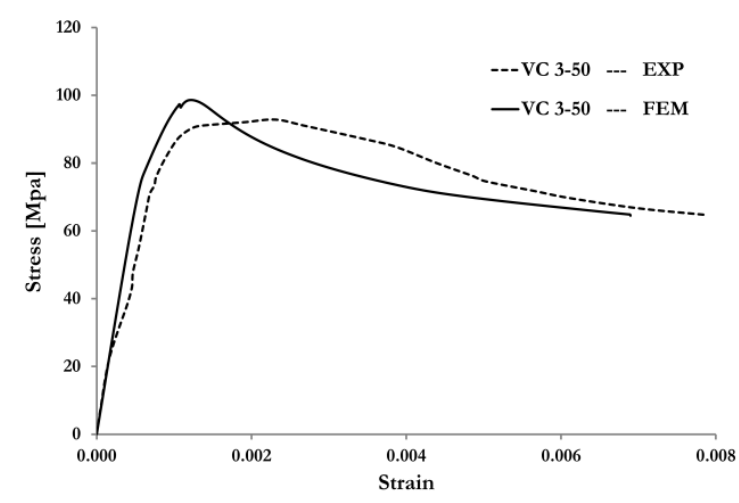

(b)

Fig. 12: The average axial compressive stress -s train curves, a-VC0.3-30, b-VC3.0-50 


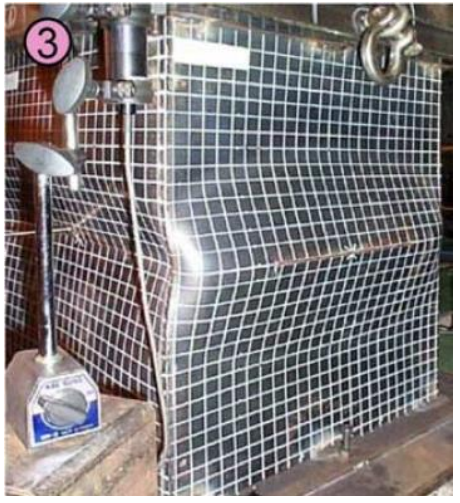

(a)

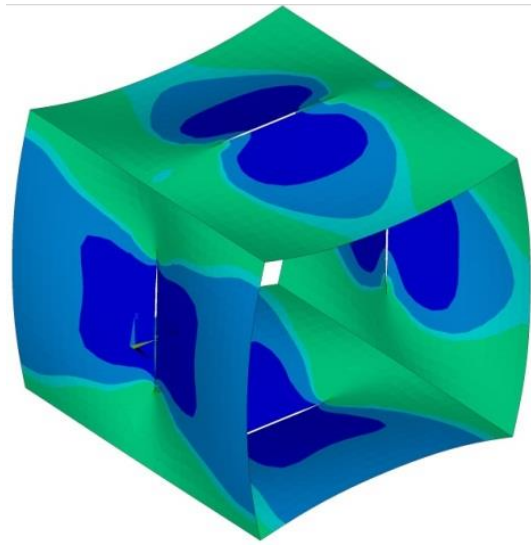

(b)

Fig. 13: Experimentally and numerically obtained collapse modes of the VC3.0-50 model, a-Experiment by Paik, b-ANSYS result by authors

\section{Ultimate strength formulation}

\subsection{Intact stiffened panels}

Different forms of closed-form empirical formulas have been introduced so far to calculate the ultimate strength of stiffened steel plates. One of the most popular formula forms in this area has been provided by Lin (1985). The general form of this formula for stiffened steel plates under in-plane compression is as follows. In this formula, normalized compressive strength is a function of the parameters $\beta$ (plate slenderness ratio) and $\lambda$ (column slenderness ratio). Later, Paik and Thayamballi (1997) used the same form to express another closed-form empirical formula.

$$
\begin{aligned}
& \frac{s_{U l t}}{s_{Y s e q}}=\frac{1}{\sqrt{C_{1}+C_{2} b^{2}+C_{3} l^{2}+C_{4} b^{2} l^{2}+C_{5} l^{4}}} \\
& b=\frac{B}{t_{p}} \sqrt{\frac{s_{Y_{P}}}{E}} \\
& l=\frac{L}{p r} \sqrt{\frac{s_{Y_{S e q}}}{E}} \\
& r=\sqrt{\frac{I}{b t+b_{f} t_{f}+h_{w} t_{w}}} \\
& s_{Y_{S e q}}
\end{aligned}
$$

The values of $C_{1}$ to $C_{5}$ by Lin's formula are respectively $0.960,0.176,0.765,0.131$, and 1.046 . On the other hand, $\mathrm{C}_{1}$ to $\mathrm{C}_{5}$ values by the formula of Paik and Thayamballi are $0.995,0.170,0.936,0.188$, and -0.067 . The same form of formula is also used in the present paper. A total of 213 stiffened panels have been modelled and analysed using the ANSYS software. From the 213 panels, 112 cases were selected to include cracks of various sizes. The geometric ranges of the analysed stiffened panels are as follows:

$$
\begin{array}{lccc}
L=1500-5700 \mathrm{~mm} & b=500-1000 \mathrm{~mm} \\
t=8-32 & \mathrm{~mm} & h_{w}=125-1236 \mathrm{~mm} \\
t_{w}=4-25 & \mathrm{~mm} & b_{f}=44-418 \mathrm{~mm} \\
t_{f}=4-34 & \mathrm{~mm} & & \\
b=0.6887-4.0 & l=0.0483-0.9657
\end{array}
$$


A series of elastic-plastic large deflection analyses is performed on all models. The average stress-average strain relation and thus the ultimate compressive strength are obtained for them. To avoid a lengthy article, the average axial compressive stress-strain curves of stiffened panels are not presented here.

According to these numerical data, regression analysis is programmed using the MATLAB environment (The MathWorks Inc., 2008) based on the algorithm explained by Khedmati et al. (2010) to determine coefficients $C_{1}$ to $\mathrm{C}_{5}$. Based on regression analysis results, the ultimate strength formula of intact stiffened steel panels is obtained as follows:

$\frac{s_{U l t}}{s_{Y s e q}}=\frac{1}{\sqrt{1.2534+0.0706 b^{2}+0.0068 l^{2}+0.1959 b^{2} l^{2}+0.3752 l^{4}}}$

A comparison between the results of finite element analysis output and the recent closed-form empirical formula for the 213 analysed models is presented in Fig. 14. In this figure, a proper agreement can be observed between the results of finite element analysis and the recent closed-form empirical formula.

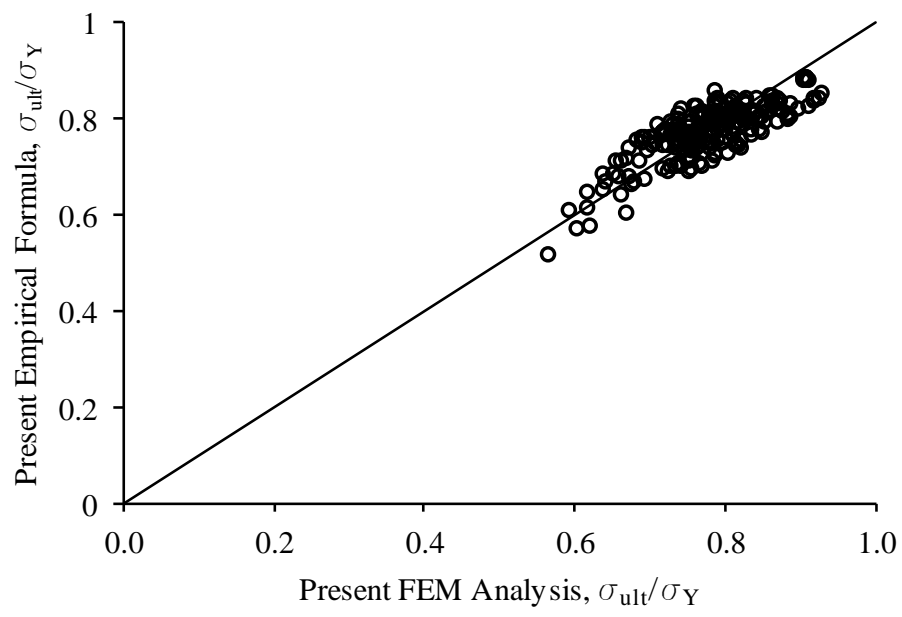

Fig. 14: Comparis on of the non-dimensionalised ultimate compressive strength values for intact stiffened panels

In order to compare the results, the variations of non-dimensionalized ultimate strength values, as a function of the $\lambda$ for two cases of $\beta$, are presented in Fig. 15. The empirical formula proposed by Paik and Thayamballi (1997) is also showed in this figure.

Therefore, based on comparisons, it can be said that the proposed closed-form empirical formula can properly present the ultimate strength values for the intact stiffened panels.

\subsection{Ultimate compressive strength of cracked stiffened panels and collapse behaviour}

The existence of cracks can reduce the ultimate strength of structural components. In this section, the closed-form empirical formula for the calculation of the ultimate compressive strength of steel-stiffened panels is presented using the results of finite element analysis. For this purpose, cracks of 12 different lengths in 112 selected panels are generated. A total of 1,344 stiffened cracked panels to calculate ultimate compressive strength are modelled and analysed. According to Fig. 2, 2. $\mathrm{a}_{\mathrm{p}}$ and $\mathrm{a}_{\mathrm{w}}$ indicate the crack length in plate and stiffener res pectively. The geometric ranges of the considered cracks are as follows:

$2 . a_{p} / b=0.044-0.764$

$a_{w} / h_{w}=0.022-0.802$

In the present paper, the ultimate strength formula of the cracked panels is defined as the product of ultimate strength of intact panel, as indicated in Eq. (12) and one coefficient. This coefficient is presented as a function of $A_{C} / A_{0}$. In this function, $A_{C}$ is the value of the remaining cross-sectional area of the cracked panel and $A_{0}$ is the value of the intact cross-sectional area of the panel. 
It was attempted to provide the most proper form of function based on regression analysis through the comparison of different functions.

The most proper coefficient to calculate the ultimate compressive strength of cracked panels is obtained as follows:

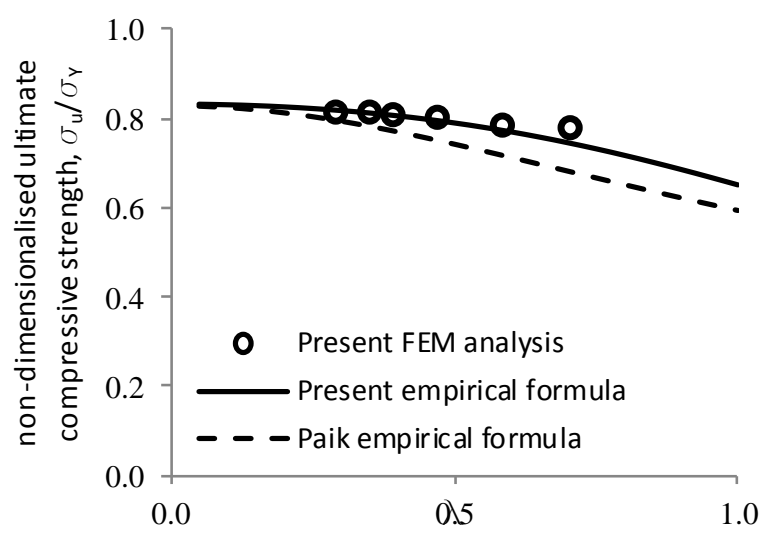

(a)

Fig. 15: Non-dimensionalised ultimate strength values as a function of $\lambda$, comparis on between present empirical formula by FEM results and Paik empirical formula, a) $\beta=1.653$, b) $\beta=2.055$

$$
\begin{aligned}
& f\left(\frac{A_{C}}{A_{0}}\right)=0.2676+0.6045\left(\frac{A_{C}}{A_{0}}\right)^{0.5}+2.2742\left(\frac{A_{C}}{A_{0}}\right)-0.8514\left(\frac{A_{C}}{A_{0}}\right)^{1.5} \\
& A_{C}=\left(b-2 a_{p}\right) t+\left(h_{w}-a_{w}\right) t_{w}+b_{f} t_{f} \\
& A_{0}=b t+h_{w} t_{w}+b_{f} t_{f}
\end{aligned}
$$

The comparis on between the results of finite element analysis output and the recent closed-form empirical formula for a total of 1,344 analysed models is shown in Fig. 16. In this figure, a strong agreement can be observed between the results of finite element analysis and the recent closed-form empirical formula. Accordingly, it can be said that empirical closed-form formula would properly present the ultimate strength values for cracked stiffened plates. In Table 3, the collapse modes of one of the stiffened panels with varying crack sizes at the ultimate strength level and at the end of calculations are shown.

Two phenomena can be described according to the figures of this table. Fig. 17 is related to Set 8 of Table 3 . After the ultimate strength point to the end of analysis, unloading (stress removal) has occurred in one part of the stiffened panel, while localized plastic deformation has simultaneously occurred in other parts of the panel. This behaviour similarly occurs in all the stiffened panels under compression, including both intact and cracked panels, due to the increase in crack length. Fig. 18 shows the collapse mode at ultimate strength level in Set 2 and Set 10 of this panel. As shown in this figure, at the two ends of the stiffened panel and far from crack point, unloading (stress removal) occurs with increased crack length, while localized plastic deformations could be observed at crack point.

As shown in the verification section, the existence of cracks in steel structures also can reduce the ultimate tensile strength. In this section, a formula is presented to calculate the ultimate tensile strength of steel-stiffened panels with crack damage. A series of non-linear finite element analyses has been implemented. As previously mentioned, the material property is assumed to be elastic-perfectly plastic. This is because, based on IACS (2008), the failure mode of stiffened panels in tension is only the elastic-perfectly plastic mode. Assuming this kind of material property, the values of the ultimate tensile strength of all the stiffened steel panels in intact condition will be equal to yield stress value or $\left(\sigma_{\mathrm{Ult}} / \sigma_{\mathrm{Yseq}}\right)_{\text {intact }}$ will be equal to unity.

Ultimate strength formulation of stiffened panels under in-plane compression or ten sion with cracking damage 


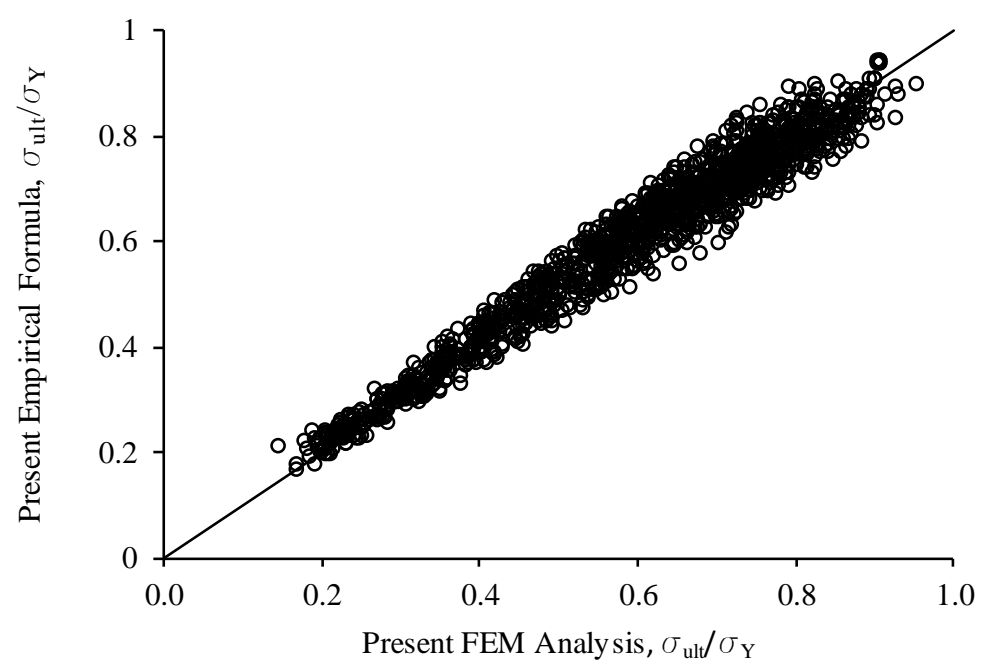

Fig. 16: Comparison of the non-dimensionalised ultimate compressive strength values for cracked panels

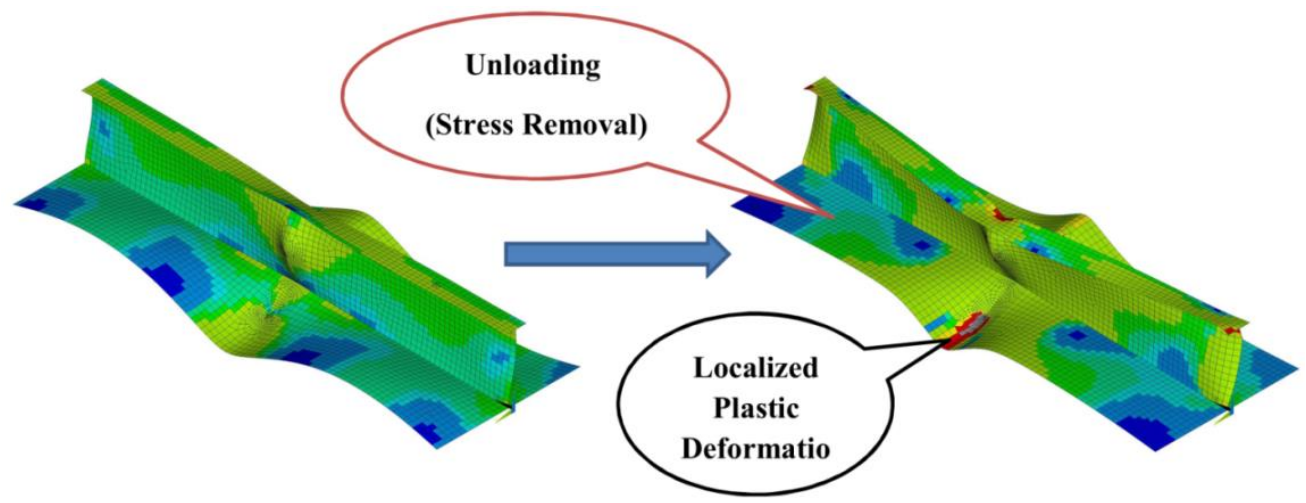

Deflection mode at the ultimate strength level

Deflection mode at the End of analysis

Fig. 17: Unloading and localised plastic deformations in Set 8 of selected stiffened panel

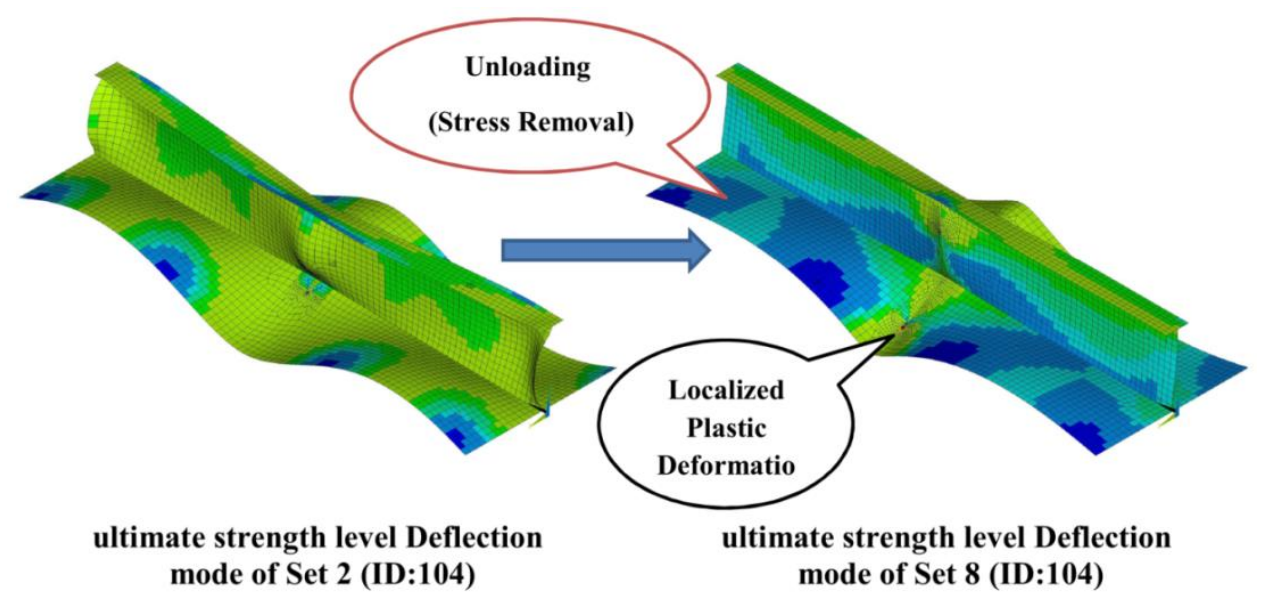

Fig. 18: Unloading and localised plastic deformations in the selected panel with increasing crack length 
Table 3: Ultimate strength mode and final collapse mode of one of the stiffened panels obtained by the FEM

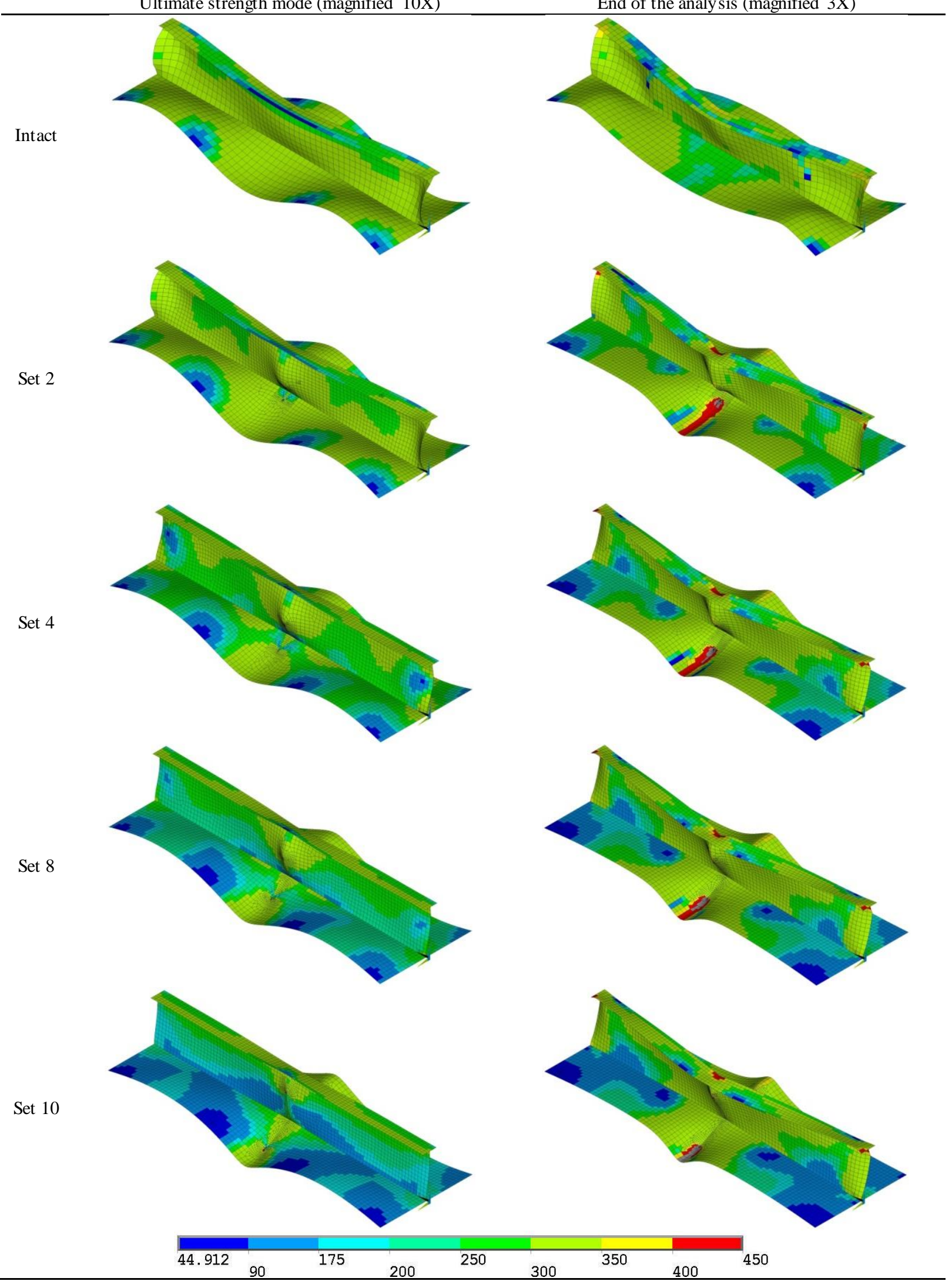




\subsection{Ultimate tensile strength of cracked stiffened panels}

To achieve the ultimate tensile strength formula, 112 panels selected in the previous section were used. The two smallest and largest crack sizes were not used for calculating the ultimate tensile strength. Finally, a total 1,120 stiffened cracked panels were modelled and analysed. Similar to compressive condition, the general form of Eq. (14) are applied to express the closed-form empirical formula of ultimate tensile strength. It is only sufficient to present a formula for $\mathrm{f}\left(\mathrm{A}_{\mathrm{C}} / \mathrm{A}_{0}\right)$ coefficient. The most appropriate coefficient to calculate ultimate tensile strength of the cracked panels is as follows:

$f\left(\frac{A_{C}}{A_{0}}\right)=0.1486-0.0405\left(\frac{A_{C}}{A_{0}}\right)^{0.5}+1.7563\left(\frac{A_{C}}{A_{0}}\right)^{1.5}-0.8509\left(\frac{A_{C}}{A_{0}}\right)^{3.5}-0.0483\left(\frac{A_{C}}{A_{0}}\right)^{5.5}$

The comparis on between the results of finite element analysis output and recent closed-form empirical formula for a total of 1,120 analysed models is shown in Fig. 19. In this figure, a strong agreement can be seen between the results of finite element analysis and the recent closed-form empirical formulas. Accordingly, it can be said that empirical closed-form formula can properly provide the ultimate strength values for cracked stiffened plates.

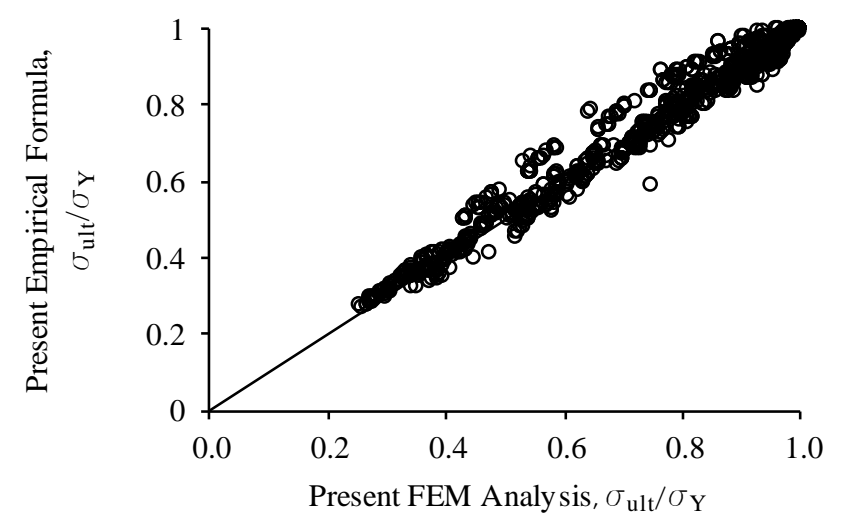

Fig. 19: Comparis on of the non-dimensionalised ultimate tensile strength values for cracked panels

\subsection{Comparison with Paik's formula for cracked panels}

Different forms of empirical equations are presented for calculating the ultimate strength of cracked panels. Among them, the most famous form is the equation proposed by Paik and Kumar (2006) as follows:

$s_{x u}=\frac{A_{C}}{A_{0}} s_{x u o}$

Where $\sigma_{\mathrm{xu}}$ and $\sigma_{\mathrm{xu} 0}$ are respectively the ultimate strength of cracked and non-cracked (intact) panels. In this form of equation, there is a direct relationship between the reduction of ultimate strength due to crack and reduction of cross-sectional area due to crack. In this equation, the ultimate strength of intact panel is equal to the yield strength in tension, and can be obtained from Eq. (6) with Paik coefficients in compression. Also, Paik and Kumar (2006) numerically analysed a stiffened panel with cracks under tension and compression. In this section, a comparison is made between the proposed empirical equations and the results obtained by Paik and Kumar (2006).

In case of compressive strength, a stiffened panel with $2460 \times 900 \times 21 \mathrm{~mm}$ plate, $210 \times 12 \mathrm{~mm}$ web, and $100 \times 15$ $\mathrm{mm}$ flange was analysed by them. They reported that the intact panel has $271.76 \mathrm{MPa}$ ultimate strength. Two cracks of different lengths were created in the plate and the stiffener. Two types of cracks-single and double cracks - were considered by them. Double crack is like the case considered in Fig. 2. In Table 4, the ultimate strengths obtained by the present empirical formula, Paik's formula, and Paik's FEM analysis are compared. This comparis on is also shown in Figs. 20 and 21. 
Table 4: Comparison between Paik results and present empirical formula in compressive strength

\begin{tabular}{|c|c|c|c|c|c|}
\hline \multicolumn{2}{|c|}{ Crack Size } & Crack ratio & \multicolumn{2}{c|}{ Paik Results $(\mathrm{MPa})$} & \multirow{2}{*}{ Present Formula (MPa) } \\
\cline { 1 - 4 } $2 \mathrm{a}_{\mathrm{p}} / \mathrm{b}$ & $\mathrm{a}_{\mathrm{w}} / \mathrm{h}_{\mathrm{w}}$ & $\mathrm{A}_{\mathrm{c}} / \mathrm{A}_{0}$ & Formula & FEM & \\
\hline 0.1 & 0.1 & 0.907 & 246.363 & 271.488 & 278.261 \\
\hline 0.2 & 0.2 & 0.813 & 220.965 & 259.259 & 258.758 \\
\hline 0.3 & 0.3 & 0.720 & 195.568 & 233.170 & 238.059 \\
\hline 0.4 & 0.4 & 0.626 & 170.170 & 206.266 & 216.156 \\
\hline 0.5 & 0.5 & 0.533 & 144.773 & 178.818 & 193.058 \\
\hline
\end{tabular}

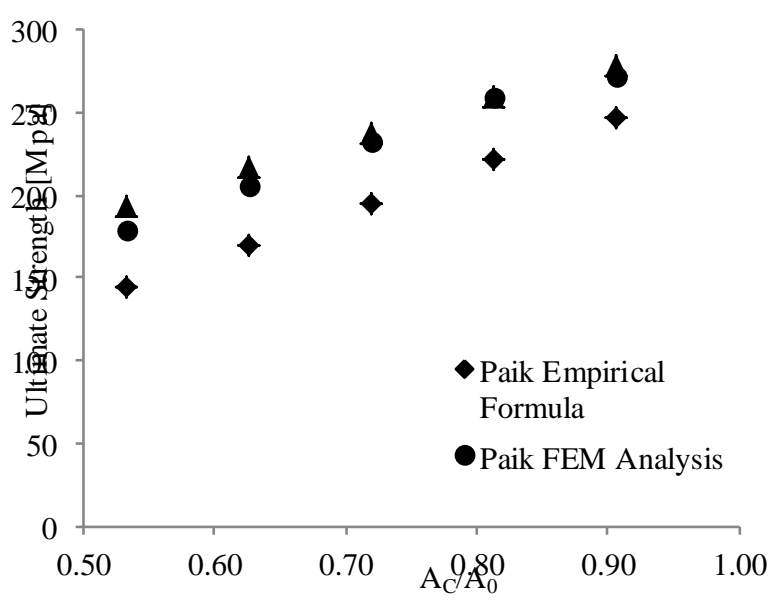

Fig. 20: Comparis on between Paik results and present empirical formula as a function of cross sectional area ratio

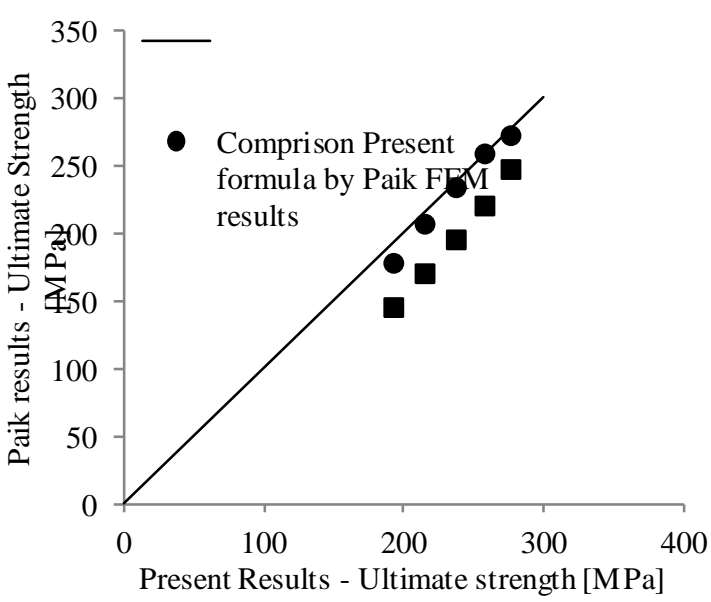

Fig. 21: Comparis on between Paik results and present empirical formula

As can be seen, strong agreement is revealed between Paik's FEM analysis and the present empirical equation. The results obtained by Paik's empirical formula are lower than those obtained by the present formula and Paik's FEM analysis. The difference between Paik's formula and the present formula is bigger for larger crack sizes. Based on these comparis ons, it can be said that the present empirical equation can estimate the ultimate compres sive strength more accurately than Paik's formula can.

In case of tensile strength, a stiffened panel with $1600 \times 800 \times 15 \mathrm{~mm}$ plate and $150 \times 12 \mathrm{~mm}$ web was analysed by Paik and Kumar (2006). Using Eq. (18), the following equation can be used for predicting the ultimate tensile strength of cracked panels:

$s_{x u}=\frac{\left(b-2 a_{p}\right) t s_{Y p}+\left(h_{w}-a_{w}\right) t_{w} s_{Y s}}{b t+h_{w} t_{w}}$

Where $\sigma_{\mathrm{Yp}}$ and $\sigma_{\mathrm{Ys}}$ are the plate and stiffener yield stress.

In Table 5, comparis on between ultimate strengths obtained by the present empirical formula, Paik's formula, and Paik's FEM analysis are shown. Like the previous case, the results of the present formulation and Paik's FEM analysis are close, but Paik's formula determines a lower ultimate strength. On the whole, it can be said that the results of the present empirical equation are more accurate than those obtained by Paik's formula.

Table 5: Comparison between Paik results and present empirical formula in tensile strength

\begin{tabular}{|c|c|c|c|c|c|c|}
\hline \multicolumn{2}{|c|}{ Crack Size } & & & \multicolumn{2}{|c|}{ Paik Results [MPa] } & \multirow{2}{*}{ Present Formula [MPa] } \\
\hline 2cp & aw & Ac/A0 & $\sigma_{\mathrm{Y}}$ & Paik formula & Paik FEM & \\
\hline 50 & 25 & 0.924 & 249.7 & 230.701 & 246.8 & 247.97 \\
\hline 150 & 75 & 0.772 & 249.7 & 192.703 & 212.9 & 236.85 \\
\hline
\end{tabular}




\section{Conclusion}

The development of closed-form formulations for predicting the ultimate compressive and tensile strength of stiffened steel panels under axial loads with crack damages is the main aim of the present paper. Extensive numerical results on stiffened panel structures, obtained through a series of elastic-plastic large deflection FEM analyses by varying the size of cracking damage, were used for the present purpose.

Three closed-form empirical formulas were presented for the calculation of ultimate strength. The first formula presents the ultimate compressive strength of intact stiffened panels. For this purpose, one of the formulas previously mentioned in this context was used. The coefficients of the formula were updated using numerical analysis results based on the regression method. The second formula is used to calculate the ultimate compressive strength of cracked panels. The formula presented in this case is the product of a coefficient with the compressive strength of intact stiffened panels. This coefficient is a function of the remaining cross sectionalarea of the cracked panel to the intact cross-sectional area of the panel. The third formula is used to calculate the tensile strength of cracked panels. The general form of this formula, like the previously mentioned mode coefficient, is a functio $\mathrm{n}$ of the remaining cross-sectional area to the primary cross-sectional area. This is because normalized ultimate tensile strength of intact panels is equal to unity.

The accuracy of derived formulations was checked by comparison with numerical results. It was found that the presented empirical formulas can yield an accurate prediction of the ultimate strength of cracked stiffened steel panels in compression or tension. The empirical formulations derived in the present study will be useful for the ultimate-strength-based reliability and risk analyses of civil and marine steel structures like ships and bridges.

\section{References}

ANSYS (2007): ANSYS user's manual, version 11, Houston: Swanson Analysis Systems Inc.

Bayatfar, A., Khedmati, M. R., Rigo, P. (2014): Residual ultimate strength of cracked steel unstiffened and stiffened plates under longitudinal compression, Journal of Thin-Walled Structures, Vol. 84, pp. 378-392. https://doi.org/10.1016/j.tws.2014.07.002

Cui, C., Yang, P., Xia, T., Du, J. (2016): Assessment of residual ultimate strength of cracked steel plates under longitudinal compression, Journal of Ocean Engineering, Vol. 121, pp. 174-183. https://doi.org/10.1016/i.oceaneng.2016.05.035

Fujikubo, M., Harada, M., Yao, T., Khedmati, M. R., Yanagihara, D. (2005): Estimation of ultimate strength of continuous stiffened panel under combined transverse thrust and lateral pressure: part 2 (continuous stiffened panel), Journal of Marine Structures, Vol. 18, pp. 411-427. https://doi.org/10.1016/j.marstruc.2005.08.004

Hu, Y., Cui, W., Pedersen, P.T. (2004): Maintained ship hull Xcgirxcder ultimate strength reliability considering corrosion and fatigue, Journal of Marine Structures, Vol. 17, pp. 91-123. https://doi.org/10.1016/j.marstruc.2004.06.001

IACS (2008): Common structural rules for double hull oil tankers, International Association of Classification Societies.

Khedmati, M. R., Zareei, M. R., Rigo, P. (2010): Empirical formulations for estimation of ultimate strength of continuous stiffened aluminium plates under combined in-plane compression and lateral pressure, Journal of Thin Walled Structures, Vol. 48, pp. 274-289. https://doi.org/10.1016/j.tws.2009.10.001

Kmiecik, M., Jastrzebsky, T., Kuzniar, J. (1995): Statistics of ship plating distortions, Journal of Marine Structures, Vol. 8, pp. 119-32. https://doi.org/10.1016/0951-8339(94)00014-J

Lin, Y.T. (1985): Ship longitudinal strength, Ph.D. Thesis, Department of Naval Architecture and Ocean Engineering, University of Glasgow, Scotland.

Margaritis, Y., Toulios, M. (2012): The ultimate and collapse response of cracked stiffened plates subjected to uniaxial compression, Journal of Thin-Walled Structures, Vol. 50, pp. 157-73. https://doi.org/10.1016/j.tws.2011.09.008

Paik, J.K., Thayamballi, A.K., (2002): Ultimate strength of ageing ships, Journal of Engineering for the Maritime Environment, Vo. 216(M1), pp. 57-77. https://doi.org/10.1243/147509002320382149

Paik, J. K., Thayamballi, A. K. (2003): Ultimate limit state design of steel-plated structures, John Wiley \& Sons (Chichester), ISBN: 978-0-471-48632-9.

Paik, J. K, Thayamballi, A. K., Lee, J. M. (2004): Effect of initial deflection shape on the ultimate strength behavior of welded steel plates under biaxial compressive loads, Journal of Ship Research, Vol. 48, pp.45-60. 
Paik, J. K. and Kumar, Y. V. S. (2006): Ultimate strength of stiffened panels with cracking damage under axial compression or tension, Journal of Ship Research, Vol. 50, pp. 231-238.

Paik, J. K. (2008): Residual ultimate strength of steel plates with longitudinal cracks under axial compression: experiments, Journal of Ocean Engineering, Vol. 35, pp. $1775-83$. https://doi.org/10.1016/i.oceaneng.2008.08.012

Paik, J. K. (2009): Residual ultimate strength of steel plates with longitudinal cracks under axial compression: nonlinear finite method investigations, Journal of Ocean Engineering, Vol. 36, pp. $266-76$. https://doi.org/10.1016/i.oceaneng.2008.12.001

Rahbar-Ranji, A., Zarookian, A. (2014): Ultimate strength of stiffened plates with a transverse crack under uniaxial compression, Journal of Ships Offshore Structures, Vol. 10, pp. 416-425. https://doi.org/10.1080/17445302.2014.942078

The MathWorks Inc. (2008): MATLAB user's guide, South Natick (MA): The MathWorks, Inc.

Wang, F., Cui, W. C., Paik, J. K. (2009): Residual ultimate strength of structural members with multiple crack damage, Journal of Thin-Walled Structures, Vol. 47, pp. 1439-1446. https://doi.org/10.1016/j.tws.2009.07.013

Wang, F., Paik, J. K., Kim, B. J., Cui, W., Hayat, T., Ahmad, B. (2015): Ultimate shear strength of intact and cracked stiffened panels, Journal of Thin-Walled Structures, Vol. 88, pp. 48-57. https://doi.org/10.1016/j.tws.2014.12.001

Xu, M. C., Garbatov, Y., Guedes Soares, C. (2014): Residual ultimate strength assessment of stiffened panels with locked cracks, Journal of Thin-Walled Structures, Vol. 85, pp. 398-410. https://doi.org/10.1016/i.tws.2014.09.011 